\title{
AUTISMO E VÍCIOS
}

Chantal Lheureux-Davidse

Université Paris Diderot, Paris, França.

Psicóloga clínica, psicanalista, mestre de conferências na Université Paris Diderot.

Tradução Márcio de Oliveira Bezerra Escritor, tradutor e intérprete.

RESUMO: A instalação de uma forma identificadora e do sentimento de existência em um corpo permanece problemática para as pessoas acometidas de autismo ou vícios. O refúgio dentro dos pensamentos ou de uma dispersão psíquica evita o contato com as vivências catastróficas, mas leva a um processo de desmantelamento sensorial e uma desconstrução da imagem do corpo, em níveis diferentes segundo cada caso. A anulação prolongada da consciência das sensações corporais provoca tais angústias por aniquilamento que o recurso urgente a sensações fortes e dolorosas restaura provisoriamente o sentimento de existência.

Palavras-chave: Vícios, autismo, consciência das sensações corporais, sentimento de existência.

ABSTRACT: Autism and addictions. Placing into the body an identifying form and the feeling of existence remains problematic for those suffering from autism or addiction. The refuge inside the thoughts or in psychic dispersion avoids the contact with catastrophic experiences, but leads to a process of sensorial dismantling and a deconstruction of the body image, in different degrees in each case. The prolonged effacement of the consciousness of body feelings provokes such angst by annihilation that an immediate return to the strong and painful feelings temporarily restores the feeling of existence.

Keywords: Addiction, autism, conscience of body sensations, feeling of existence.

DOI - http://dx.doi.org/10.1590/S1516-14982015000100003 
A s questões da forma e do informe estão presentes nas problemáticas aditivas, como no autismo. Quais ligações e diferenças podemos encontrar entre o autismo e os vícios a respeito de tais questões? A partir de casos clínicos provindos de ambos os domínios, propomos testar a hipótese da existência de um âmago autístico em certas pessoas que sofrem de algum tipo de vício alimentar ou por emoções fortes. Falaremos da perda do sentimento de existência e de suas consequências no autismo e nas patologias aditivas. Então, apresentarei a especificidade das zonas corporais anuladas durante o desmantelamento sensorial nas patologias autísticas, bulímicas e anoréxicas, apoiando-me nas etapas de construção da imagem do corpo. Precisaremos os diferentes fins da dispersão psíquica durante os momentos de clivagem. E, por fim, desenvolverei a questão da urgência do recurso às sensações fortes em pacientes acometidos de angústias catastróficas.

\section{A PERDA DO SENTIMENTO DE EXISTÊNCIA EM SEU CORPO}

As compulsões aditivas obedecem, no mais das vezes, a um processo que tenta garantir um sentimento de existência, apesar da tendência por uma dispersão psíquica podendo levar a efeitos de desmantelamento sensorial. O "desmantelamento sensorial" foi essencialmente evidenciado por Donald Meltzer a partir de casos de autismo (MELTZER, BREMNER, HOXTER, WITTENBERG, 1980). Esta expressão designa a perda progressiva da consciência das sensações corporais que em geral se ligam no que ele chama "consensualidade”. Produz-se, então, uma perda do "ego corporal" no sentido freudiano e a anulação progressiva do "sentimento de existência continuamente" no sentido winnicotiano (WINNICOTT, 1971, apud PONTALIS, 1975).

Freud escreveu em 1923 em "Ego e id”: "O ego é antes de tudo corporal, ele não é apenas um ser de superfície, ele próprio é a projeção de uma superfície” (FREUD, 1922-3). Na tradução inglesa de 1927, adiciona-se com a autorização de Freud: “Isto é: o ego é finalmente derivado de sensações corporais, principalmente daquelas cuja fonte encontra-se na superfície do corpo. Ele pode ser assim considerado como uma projeção mental da superfície do corpo..." (FREUD, 1991 (1921-1923).

Por que a questão da consciência das sensações corporais é tão essencial para sentir-se existir?

Durante as clivagens entre a psiquê e o soma, a perda da consciência das sensações vividas pelo corpo impede que a pessoa se sinta concernida por si mesma e bloqueie toda e qualquer comunicação interpessoal.

O fenômeno leva a um tipo de pensamento essencialmente associativo que se distancia aos poucos de todo pensamento lógico de causa e efeito. Isto é, o 
pensamento funciona então por efeito de resonância, fora do contexto de toda temporalidade histórica. Este pensamento essencialmente associativo, se não se liga com leveza a um pensamento lógico contextualizado, pode derivar pouco a pouco até a perda de todo laço com o ego corporal. Os pensamentos giram em círculos e aceleram-se em seu movimento até atingir efeitos de saturação ou vertigem. A relação psiquê/soma é de alguma maneira cortada. Os pensamentos não podem mais acalmar-se. A imagem do corpo desfaz-se progressivamente até o ponto em que ataques de pânico ligados ao fato de não poder mais sentir sua existência corporal levem a angústias insuportáveis por aniquilamento (WINNICOTT, 1975/1963, p.35-44).

Associada à perda de uma capacidade em organizar o pensamento dentro de uma lógica de causa e efeito, a perda de contato com as sensações corporais bloqueia toda e qualquer capacidade de iniciar um movimento. Às vezes, a motricidade espontânea não pode mais se exercer. Somente a ação dos pensamentos pode provocar um movimento, mas de forma mecânica. Em outros casos, a motricidade voluntária pode vir a ser impossível de ser realizada.

A perda da consciência das sensações corporais impede a implicação de si. Toda escolha pessoal torna-se, então, impossível. A comunicação com outrem perde assim toda a espontaneidade. A resposta a uma pergunta será feita de modo automático, ou com certo atraso, até o momento em que se possa estar implicado. Muitas vezes a resposta com atraso poderia ter sido bastante adequada se tivesse sido enunciada espontaneamente no momento certo. A impressão de se estar vivendo em defasagem em relação ao corpo é então evocada. Os comandos motores não podem mais responder aos desejos organizados pelo pensamento, em especial para iniciar um movimento que perdeu sua lógica de desencadeamento de causa e efeito.

\section{AS ZONAS CORPORAIS ANULADAS DURANTE O DESMANTELAMENTO SENSORIAL}

Existiria uma especificidade das zonas corporais anuladas durante o desmantelamento sensorial, segundo as organizações psicopatológicas? O estudo dos casos clínicos, em sua singularidade, esclarece-nos sobre este quesito.

Se a angústia pelo vazio interior e o temor pela dispersão de fora do corpo estão bastante presentes durante as crises de bulimia, são a angústia por deformação e invasão do corpo que predominam no discurso das pessoas acometidas de anorexia.

No autismo, são as angústias por dilaceramento de diferentes partes do corpo que se concretizam, por exemplo, o dilaceramento das extremidades do corpo e da zona bucal. 
Temores de perda do sentimento de existência estão ligadas à anulação provisória da consciência das sensações corporais na medida em que se desconstrói a imagem do corpo. O refúgio nos pensamentos e a fixação nos movimentos de seus pensamentos fazem perder o contato com a consciência das sensações corporais, nos momentos de clivagem entre a psiquê e o soma. Não é a representação do corpo que se encontra em perigo de anulação, mas a consciência das sensações corporais.

Que seja no autismo, na bulimia ou na anorexia, existem diferentes níveis de anulação da imagem do corpo de acordo com a amplitude do desmantelamento. Quando a anulação de certas partes do corpo prolonga-se, ela pode estender-se para outras zonas até que a angústia por aniquilamento imponha-se e ative uma busca urgente pela reversibilidade do processo. As partes implicadas podem ser variáveis de acordo com cada caso e, por vezes, comuns entre as três patologias. As últimas partes do corpo integradas na imagem do corpo serão os primeiros defeitos no momento do desmantelamento sensorial.

A elaboração de uma situação traumática não integrável pela psiquê pode levar a uma desconstrução da imagem do corpo até suas origens.

O desmantelamento sensorial associado à perda de conexão entre os sentidos pode alternar-se com um remanejamento durante o qual a imagem do corpo se reconstrói nos lugares onde ela havia sido anulada da consciência. Este processo reversível é normal enquanto for operado com leveza e desde que não acarrete uma clivagem destruidora entre psiquê e soma.

Nos casos mais patológicos, como na bulimia grave ou no autismo, o remanejamento sensorial só se faz em muitos casos através da dor e de sensações fortes. Esta dor é buscada compulsivamente, após uma série de angústias por aniquilamentos ligados à perda do sentimento de existência em seu corpo (BARABE \& LHEUREUX-DAVIDSE, 2004). A reanimação sensorial pode implicar toda a zona corporal anulada para a percepção. O estudo do processo de formação da imagem do corpo esclarece-nos sobre este tema.

\section{A IMAGEM DO CORPO PARA AS CRIANCGAS AUTISTAS}

Geneviève Haag descreve bem as etapas de construção da imagem do corpo a partir da clínica do autismo (HAAG, 1994, p.40-58). Lembremos as etapas principais: o sentimento de existência de uma defasagem precede o sentimento de existência no interior. Igualmente, o investimento da razão deixa escapar o investimento do restante do corpo.

Quanto ao investimento do olhar, ele constrói-se no bebê durante a harmonização com o olhar materno se este for vivaz e presente - isto é, se manifesta as qualidades de brilho e de movimento. Durante esta troca que tanto o bebê 
quanto a mãe procuram, o bebê é levado pelos braços da mãe, que apoia suas costas e sua nunca com doçura, firmeza e ardor. Assim, a constituição das costas, deste segundo plano vertical de segurança, faz-se em conjunto com a instalação do olhar. Como se as costas se tornassem o fundo dos olhos e constituíssem um portador de segurança durante a criação do laço entre um e outro pelo olhar. É nestas condições que a tridimensionalidade pode se instalar. O corpo torna-se capaz de guardar boas experiências e interiorizá-las.

Quando uma criança autista olha bem perto os olhos de outra pessoa, ela busca certamente um fundo sólido, doce e aliviador, indo assim inspecionar em conjunto com a nuca, o segundo plano da cabeça ou a parte de cima das costas para verificar se ele é esburacado ou plano. Assim, ele verifica, lançando-se dentro do olhar do outro, se ele está contido ou se corre o risco de ser tragado por um buraco negro sem fundo, como descrito por Francès Tustin (TUSTIN, 1986/1989). Quando o olhar se instala, o eixo vertical das costas serve de dobradiça entre os lados direito e esquerdo do corpo, primeiramente na altura da cabeça e depois ao longo do corpo. Depois, a investida da dobradiça horizontal "prenderá" a cabeça ao resto do corpo. Movimentos de articulação entre as partes de cima e de baixo do corpo são testemunhas disto. Em seguida, as extremidades do corpo, das mãos e dos pés se prendem ao resto da imagem do corpo já formada. E então a investida da pele que contém o conjunto do corpo permitirá que os orifícios sejam em seguida esfincterizados psiquicamente.

A imagem do corpo formada não é mais uma soma das partidas conectadas umas às outras, mas torna-se integral graças a uma consensualidade. Isto é, cada parte é um laço entre os demais. Os sentidos estão conectados entre si, ainda que diferenciados ao mesmo tempo.

Quando a imagem do corpo se forma nesta consensualidade, o sentimento de existência permite igualmente sentir-se conectado aos outros através das comunicações. Enquanto esta consensualidade não estiver funcionando, como em um trabalho de rede, a o investimento de um sentido só pode realizar-se de forma exclusiva sem poder conectar-se a outro sentido. Da mesma forma, o investimento dirigido a uma pessoa apaga aquele dirigido às demais. A permanência do objeto encontra-se desde então difícil de integrar e cada mudança representa uma ameaça de aniquilamento.

Durante o investimento da fase oral, a zona bucal constitui uma das regiões mais frágeis da imagem do corpo. Enquanto esta parte não for assumida, isto provoca a vulnerabilidade de todo o corpo, acompanhada de angústias por intrusão ou por esvaziamento.

Ademais, certas crianças que apresentam traços autísticos são tomadas pela angústia por esvaziarem-se inteiramente se o corpo delas estiver aberto: por exemplo, quando uma pequena ferida na pele ainda não é cicatrizada ou, 
ainda, quando, no banheiro, uma parte delas se despreende do corpo. Então, eles podem se identificar com este conteúdo digestivo por eles abandonado ao ponto de esquecerem o resto do corpo. É comum que a criança tomada pelo pânico lute contra suas angústias tentando tampar a privada ou verificando compulsivamente se ainda há água no aparelho sanitário e nas torneiras. Não podendo mais identificar-se consigo mesmo, ela se identifica com tudo o que se corresponda dentro de seu meio às partes de sua imagem do corpo a serem reconstituídas (LHEUREUX-DAVIDSE, 2003). Toda abertura percebida no meio externo torna-se metáfora dos orifícios corporais.

Certamente é assim que podemos entender as compulsões das crianças autistas em abrir e fechar portas ou cortinas. Elas verificam se seus orifícios do corpo ou dos olhos podem ser abertos ou fechados. Neste caso, o interior limita-se e diferencia-se do exterior e a criança permanece em segurança sem anular o exterior em suas compulsões.

Durante os processos de remanejamento sensorial, as pessoas autistas fazem uso muitas vezes a estereotipias buscando obter, por efeitos visuais, formas luminosas geométricas de movimento leve - por exemplo, mexendo os dedos diante dos olhos em direção de uma fonte de luz. Então, elas obtêm as qualidades de brilho acompanhadas de leves movimentos que as crianças normais conseguiriam nas simples trocas de olhar.

A fascinação deles pelas formas geométricas coloridas em movimento leve não seria a preparação para se sentir contido dentro de uma forma identificadora vivaz, ainda que abstrata?

Adam, um jovem autista que se exprime em uma linguagem bastante metafórica, explicou-nos que ele tinha o sentimento de ser um quadrado quando entrava em contato com suas sensações corporais. Ele descrevia o modo como ele reintegrava seu corpo pela parte de cima da cabeça, em segundo plano, e o fato de que suas costas abertas assim fechavam-se novamente. E então, precisou-nos que seu corpo era como "uma piscina insistentemente bem fechada 24 horas por dia”. Por fim ele dizia maravilhar-se com o mundo que ele parecia descobrir em toda sua beleza: Adam falava de uma "vitrine com tesouros imensos no interior". Ele utilizava o número 4 e as formas quadradas para descrever seu sentimento de conter-se em formas identificáveis e definidas. Ele podia então deixar fluir seus sentimentos.

Certas crianças autistas podem refugiar-se nas buscas sensoriais tranquilizadoras que viveram antes dos momentos catastróficos. Assim, será que as oscilações rítmicas não serviriam de eco aos ritmos cardíacos e respiratórios tranquilizadores e contínuos que o feto vivenciava dentro do útero de sua mãe? 


\section{AS ANGÚSTIAS POR VAZIO INTERIOR \\ E POR PERDA DOS LIMITES NA BULIMIA}

No caso da bulimia, estados de dispersão psíquica podem ir até a perda de contato com as próprias sensações corporais. A vivência descrita é a de um vazio interior, causado entre outros pela angústia da perda de consciência das sensações internas e por uma precariedade do sentimento de sentir-se contido dentro de seu corpo por um envelope ou um meio sólido. A existência de um interior é posta em dúvida ao ponto de suscitar um risco de aniquilamento. Estas angústias colocam em perigo o sentimento de existência.

Para estes pacientes, a anulação de um interior gera uma perda da noção de profundidade que provém das angústias espaciais. O sujeito mergulha em um estado de vulnerabilidade que reflete o período de instalação da tridimensionalidade. O corpo é vivenciado como uma folha de duas dimensões que poderia somente ter contatos superficiais, como antes da instalação do olhar. Notemos mais globalmente que é a instalação do olhar que funda toda a profundidade da relação ao outro e que dá acesso à tridimensionalidade. Mesmo se o bebê se prepara já à noção de profundidade com o tato — quando ele testa a elasticidade da pele de sua mãe exercendo leves pressões em seu seio ao se amamentar ou, por exemplo, quando ele explora a aspereza de superfícies diferentes.

Os momentos de vida interior vivenciadas por inúmeros pacientes bulímicos traduzem dificuldades de interiorização de boas experiências relacionais repetidas. Estes fenômenos levam a uma dificuldade para memorizar o que fora vivenciado para evitar o contato com lembranças de experiências dolorosas. Esta problemática reflete os estados depressivos na criança quando seus pensamentos se voltam para os pais, com os quais ela se preocupa ao ponto de esquecer sua própria existência e suas próprias experiências dolorosas. A criança não consegue sentir-se aceita por ela mesma enquanto aprende. A partir disto, ele esquece rapidamente o que aprende e perde toda capacidade de interiorização de suas boas experiências.

Os pânicos por perda do sentimento de existência ativam-se às vezes no momento em que a consciência sentir que seus limites corporais correm perigo também. As angústias por anulação de um interior ameaçam a possibilidade de continência. Somente por meio dessa possibilidade, expressa por compulsões de preenchimento, é que pode existir a tranquilização de um sentimento de existência em seus próprios limites.

Segue-se a descrição que uma jovem acometida de bulimia fazia de si:

Quando mudo de lugar, me angustio. Tenho a impressão de reduzir-me em um tubo oco posto verticalmente e que não será fechado nem por cima nem por baixo, vazio no interior. A densidade do ar é tão leve que não me sinto em segurança nem dentro nem fora. Isto me faz pensar que até meus 6 
anos de idade eu não tinha controle de mim mesma à noite. Sentia-me completamente só, especialmente quando passava as férias com meus avós. Eles ficavam comigo durante 0 ano inteiro até os meus 6 anos e durante as férias. Eu tinha a impressão de estar numa solidão profunda. Minha mãe buscou-me aos 6 anos. Ela criticava meus avós por haver-me feito comer demais. Na adolescência eu devia subir todos os dias na balança sob o olhar de meus pais situados atrás de meus ombros. Era horrível. Em outros momentos, pelo contrário, sinto que há uma pressão enorme no interior de meu corpo. Como se a densidade fosse forte demais. Tenho a impressão que meu envelope estava a ponto de rachar-se, como em um filme de ficção científica e como se houvesse muita luz no interior que se escaparia através das rachaduras.

É nestes momentos de angústia por risco de aniquilamento que as crises de bulimia desencadeavam-se.

Em certos casos de bulimia com bases autísticas, as compulsões de preenchimento atualizam-se para tentar tampar a dilatação de uma zona bucal não constituída. Em outros, estas compulsões de preenchimento podem se dar através das angústias por vazio interior. Trata-se aqui de uma dificuldade de interiorização pela perda de investida de um "interior".

Em inúmeros casos de bulimia, o peso real do corpo cumpre o ofício de memorando de um traumatismo pesado, como no caso de abusos sexuais e de experiências incestuosas.

\section{O PARADOXO DO "CHEIO DEMAIS" NA ANOREXIA}

$\mathrm{Na}$ anorexia, a apreensão da imagem do corpo é constantemente invadida por representações incestuosas inconcebíveis (RACAMIER, 1992). Para anular uma invasão psíquica e uma vivência interior de sensações de obesidade, organizam-se fobias de ingestão de certas comidas que se tornam e intragáveis no mundo real.

Tratar-se-ia de um corpo habitado por imagos paternas dolorosas demais, dos quais a criança seria depositária e guardiã. Nas representações impensáveis que buscam se manifestar sob a forma puramente alucinatória sensorialmente, como focalizações sobre uma imagem real de todo modo gorda demais, seria necessário perder no mundo real o peso psíquico inconcebível e inassimilável.

$\mathrm{Na}$ anorexia, a vivência corporal pode ser descrita como um conjunto de sensações de deformação podendo chegar à dismorfofobia ou transtorno dismórfico corporal. Trata-se, muitas vezes, de um sentimento de ser habitado por uma forma que seria perigoso assimilar-se, que deforma ao ponto da desforma (LE POULICHET, 2003) e da qual a pessoa deve se livrar a qualquer custo. 
Uma garota apresentando tendências anoréxicas relatava ao longo de seu trabalho analítico o seguinte sonho: “Estou me olhando no espelho, mas, no lugar de ver-me, vejo o corpo de minha mãe no lugar do meu. Estava tão amedrontada que acordei gritando."

Ela observava no espelho todo sinal de rugas que ela pudesse encontrar e tinha a impressão de ter quadris largos demais. Ela sentia-se obesa por dentro e procurava as provas disso no espelho; e aterrorizava-se com a ideia de que seu corpo mostraria celulites que deformariam sua silhueta. Ela vivia seu corpo como se fosse uma soma de partes que não se ligavam: "Às vezes, tenho a impressão de ter um corpo de velha. Se ultrapasso certo peso, sinto-me em perigo por cada grama que seja. Quando me vejo obesa no espelho, paro de comer até que eu volte aos limites a não serem ultrapassados. É geralmente o peso da balança que me indica isto."

A prova de um pequeno peso que não se deve ultrapassar garantiria assim uma barreira simbólica anti-incestuosa entre as gerações e evitaria as angústias por confusão dos corpos entre sua mãe e ela própria. É assim que a paciente mantinha, ao privar-se de comer, uma silhueta de antes da puberdade totalmente diferente da de sua mãe. Quando era pequena, todos a criticavam por ser gordinha. Quando ela entrou na puberdade considerada por ela mesma como precoce demais, ela se via coberta de formas que nasciam, deformavam seu corpo e que focalizavam de modo intrusivo o olhar dos outros sobre sua intimidade. Suas formas naturalmente femininas confundiam-se com as curvas criticadas durante sua infância. Ela não estava pronta para deixar-se transformar por formas femininas que mudariam toda sua silhueta a contragosto. Aparentemente ela teve de substituir um pai constantemente ausente ao lado de sua mãe. Ela ouvia todas as queixas de sua mãe ao lhe confessar sua fragilidade. Para proteger a mãe, ela saía provisoriamente de seu lugar de criança para tentar conter as angústias dela. Tomando conta dela constantemente, ela encontrava-se presa numa inversão de papéis geracionais a ponto de confundir o corpo de sua mãe com o seu. Apesar disso, ela não suportava quando lhe diziam ser o retrato de sua mãe. Lembrando-se destes momentos, ela nos dizia: "Quando lembro este período, tenho a impressão de que o clima de casa era como o interior de uma catacumba fechada, obscura e sem luz alguma. Minha mãe era frágil demais. Ela nunca soube quem era seu pai."

A questão da forma na anorexia estaria então ligada às esquivas da intrusão de uma forma alojada no interior, a qual correria o risco de deformar a imagem do corpo. O desejo de reduzir-se a uma estrutura óssea desprovida de todo traço de feminidade teria como objetivo evitar, como nos casos graves de anorexia, todo o risco de confusão geracional, risco em relação ao que seria um equivalente incestuoso. O limite de um peso impossível de ultrapassar contribuiria para a 
restauração de uma barreira psíquica anti-incestuosa protetora. A dismorfofobia tentaria reavivar, através de uma alucinação, uma imagem do corpo mortífero inanimado.

\section{OS FINS DA DISPERSÃO PSÍQUICA}

Segundo as patologias autísticas ou aditivas, as tendências à dispersão psíquica diante da clivagem entre os pensamentos e as sensações corporais têm finalidades diferentes. Nas experiências de refúgio nos pensamentos, o meio é essencialmente vivenciado como não humano (SEARLES, 1960) e mesmo às vezes como inanimado para as pessoas autistas que tiveram toda relação com outrem cortada, diferentemente do que ocorre com pessoas acometidas de vícios, que permanecem ligados ao meio humano animado.

A identificação com um mundo inanimado a reavivar-se ou com um meio não humano a reumanizar é tão forte nas pessoas acometidas de autismo que o sentimento de existência delas e de sua alteridade quase não é constituído em continuidade. Durante as fases de clivagem, as tentativas de reconstrução da imagem dos próprios corpos e da relação com o outro irão arremessá-los em buscas de qualidades ou sensações encontradas no ambiente não humano e refletirão as sensações ou qualidades normalmente vividas quando a imagem do corpo está bem constituída e na relação com o outro.

Por exemplo, as qualidades de brilho associadas aos micromovimentos provocados por estereotipias gestuais, entre seus olhos e o reflexo de uma poça d’água, serão um equivalente metafórico de uma troca de olhares a reavivar-se. Isto também vale para a qualidade de verticalidades procurada em objetos de seu meio, que prepara uma integração da qualidade de verticalidade do eixo vertebral na imagem do corpo ainda não totalmente constituído.

Enquanto que para algumas pessoas acometidas de vícios, a dispersão psíquica durante clivanges entre a psiquê e o soma continuará sendo mais facilmente afim ao meio humano. Por exemplo, a identificação com pessoas do meio é às vezes tão forte que ela atinge a anulação, a intrusão ou a deformação do ego corporal de acordo com as patologias de bulimia ou anorexia. A manutenção da existência de um ambiente humano protetor dependeria de uma suspensão do sentimento de existência em benefício de um narcisismo que se deve reconstituir a partir de um meio precário.

\section{A URGÊNCIA AO RECURSO ÀS SENSAÇÕES FORTES}

Enquanto a consciência dos limites é anulada ou perdida, produz-se um estado de indiferenciação e uma perda da sensoriedade de forma identificadora. A perda 
da consciência do espaço interno provoca muitas vezes angústias por perda dos limites corporais, originadas de angústias espaciais. Quando um longo período de perda de consciência das sensações corporais esvaiu-se, o processo de desmantelamento só é reversível através de meios sensoriais intensos. A função destes últimos é a de restaurar o mais rápido possível a consciência das sensações corporais perdidas. Para lutar contra angústias por anulação, liquefação, desabamento ou aniquilamento, a urgência de achar um sentimento de existência dentro do corpo provoca a busca precipitada de sensações fortes experimentadas no corpo (LHEUREUX, 2003).

Cremos que a dor das automutilações ou a provocada por compulsões aditivas, ou ainda a quebra dos limites, têm a mesma função reavivadora da consciência das sensações corporais, mesmo que não se trate dos mesmos locais a reanimar-se. A passagem das sensações inconscientes para as conscientes e para a percepção restaura o sentimento de existir dentro de seu corpo.

No autismo, as mordidas nas mãos são aplicadas com força ao ponto das sensações reaparecerem à consciência através da dor. Esta última restaura o sentimento de existência até suas extremidades. Quando a dobradiça horizontal não está constituída psiquicamente, a perda de consciência da parte de baixo do corpo pode levar a tentativas de reanimação sensorial inconscientes. Compulsões de bater-se nas pernas ou nos pés ou a torcer os tornozelos restauram a consciência sensorial da parte de baixo do corpo.

Os autoagarramentos musculares, externos ou internos, que lutam contra as angústias de desabamento provocam cãibras dolorosas que podem também ocupar esta função reanimadora de sensações. A busca pela dor ou de sensações fortes não representa um objetivo em si, mas um meio de obter com rapidez a restauração de sensações perdidas (LHEUREUX-DAVIDSE, 2004).

Paralelamente, em uma compulsão alimentar, a ingestão de um prato inteiro ou de todo o pacote de biscoitos parece necessária para acalmar a angústia. Na bulimia, o preenchimento compulsivo de comida em excesso só cessa com a obtenção de uma sensação consciente de náusea, dores de cabeça e de barriga. A mínima sobra esquecida corre o risco de arrefecer o sentir-se só e participa das angústias por abandono. Este efeito de limite, de borda, permite retomar a consciência de uma sensação corporal que se tranquiliza rapidamente acerca do sentimento de existência sensorial dentro de um corpo diferenciado de seu meio. Assim, os limites de contenção podem ser mais uma vez vivenciados.

Parece-nos importante acabar de uma vez por todas com o discurso de gozo masoquista nas pessoas acometidas de vícios. Efetivamente, quando elas utilizam a dor como meio de reanimação sensorial dentro da urgência para reencontrar um sentimento de existência perdido, parece-nos inadequado falar de gozo na dor. Por outro lado, é o momento de reencontro com um sentimento de existência, 
depois de angústias inomináveis de aniquilamento, que pode aparecer, às vezes ao custo da dor, um júbilo de sentir-se existir novamente dentro de seu corpo, o que nada tem a ver com gozo masoquista.

Ademais, os comportamentos sexuais aditivos buscados na urgência e em geral sem ternura, tal como as sensações fortes buscadas por práticas sadomasoquistas, podem por vezes ser entendidas como pesquisas de sensações corporais reanimadoras, restaurando rapidamente um sentimento de existência em seu corpo no âmago de momentos de angústias catastróficas. O consumo de tóxicos poderia igualmente ser analisado por este ângulo.

No âmbito terapêutico, os movimentos destruidores provocados pelo curso a sensações fortes reanimadoras podem ser pouco a pouco acompanhados pela intensidade compartilhada de momentos de maravilhamento. As metáforas tornam-se assim fontes de identificação por suas qualidades que despertam por ressonância as qualidades-de uma forma identificadora.

Parece-nos que, nestes momentos, a nominação das sensações pelo terapeuta pode colaborar para o remanejamento sensorial e desta forma favorece a passagem das sensações inconscientes para a percepção. A interpermutabilidade dos sentidos cederá lugar a uma diferenciação reencontrada de cada sentido e será o prelúdio de uma consensualidade restaurada. Isto participa da estabilidade de uma imagem corporal que é leve em relação à psique.

A relação entre o autismo e os vícios encontrar-se-ia na dificuldade de instalar uma forma identificadora estável e o sentimento de existência dentro do corpo. O refúgio nos pensamentos clivados das sensações corporais evita o contato com as lembranças de vivências catastróficas. Mas a tendência à dispersão psíquica que decorre disto pode desconstruir a imagem do corpo até sua anulação. No autismo, a dispersão psíquica conduz à identificação a um meio não humano inanimado que se deve reumanizar e reanimar. Enquanto que nos vícios, a dispersão psíquica permanece ligada a um meio humano que deve ser tornado de novo narcísico.

O desmantelamento sensorial provoca angústias por aniquilamento que ativam uma busca urgente da reversibilidade do processo. Após a anulação prolongada da consciência das sensações corporais, o recurso a sensações fortes ao custo da dor restaura provisoriamente o sentimento de existência. As zonas corporais envolvidas durante o desmantelamento sensorial reversível podem ser comuns ao autismo e aos vícios. O nível de anulação da imagem do corpo deve ser notado na singularidade de cada caso. 


\section{REFERÊNCIASS}

BARABE, N., LHEUREUX-DAVIDSE, C. (2004) “La question de la réversibilité du démantèlement chez un adulte autiste", Cliniques méditerranéennes, 70, éditions Erès.

FREUD, S. (1922-1923) "Le moi et le ça”, in (1915-1922) Essais de psychanalyse, trad. coll. P.B.P. Paris: Payot. (1921-1923) "Le moi et le ça", in (1991) Sigmund Freud, Oeuvres complètes, v.XVI, trad. coll., Paris: PUF.

HAAG, G. (1994) “Aux sources de la vie; le langage préverbal et l'émergence des représentations du corps en situation psychanalytique individuelle ou groupale avec des enfants autistes”. Actes des langage. Quand parler c'est agir, Dialogue, 23, Paris, p.40-58.

LE POULICHET, S. (2003) Psychanalyse de l'informe Dépersonnalisations, addictions, traumatismes. Paris: Flammarion, Aubier Psychanalyse.

LHEUREUX-DAVIDSE, C. (2012) “De l'agrippement sensoriel à la métaphore partagée dans la clinique de l'autisme”, Chimères, 78, p.75-85.

( 2009) "Vécus corporels chez des personnes autistes. La place du corps et de la sensorialité dans les installations en clivage", chapitre 10, Le corps vécu chez les personnes âgées et les personnes handicapées. Paris: Dunod (collection Action sociale).

(2007) "Jouer avec les mouvements, les vibrations et les rythmes dans l'émergence de la voix », Champ psychosomatique, La Voix, 48. Paris: L’Esprit du temps, p.185-203.

(2005) “Hypocondrie, paradoxalité et intensité inéprouvable”, L'hypocondrie, Champ psychosomatique, 39, Erès, éditions L’Esprit du temps, p.67-80.

(2003) L'autisme infantile ou le bruit de la rencontre, Contribution à une clinique des processus thérapeutiques, Paris: L’Harmattan.

(2003a) “L'image du corps d'une personne abusée dans son enfance”, in Détresse sociale et souffrance psychique, l'enjeu du sujet, Transhumances, 4, Presses Universitaires de Namur en Belgique, p.195-198.

(2005) “Autisme et addictions", in L'informe et l'archaÏque, Recherches en psychanalyse. Paris: éditions l’Esprit du temps, p.31-42.

MELTZER, D.; BREMNER, J.; HOXTER, S.; WITTENBERG, I. (1980) Explorations in Autism. Londres: Karnac Books.

RACAMIER, P.-C. (1992) Le génie des origines. Psychanalyse et psychoses, Paris: Payot (coll. Bibliothèque scientifique).

SEARLES, H. (1960/1986) L'environnement non humain, trad. fr. D. Blanchard, Paris: Gallimard.

TUSTIN, F. (1989) Le trou noir de la psyché, Barrières autistiques chez les névrosés, trad. Paul Chemla. Paris: Seuil. 
WINNICOTT, D. (1975/1971) Creativity and its Origins, trad. Cl.Monod et J.B.Pontalis, "La créativité et ses origines", in Jeu et réalité, Paris: Gallimard

(1963/1975) “La crainte de l'effondrement", trad. J.Kalmanovitch et M.Gribinski, in Figures du vide, Nouvelle Revue de Psychanalyse, Paris: Gallimard, 11, p.35-44

Chantal Lheureux-Davidse

chantal.lheureuxdavidse@laposte.net 